\title{
TMAS - Maritime Telemedical Assistance Service at the University Centre of Maritime and Tropical Medicine in Gdynia. The first year activity report
}

\author{
Michał Kurlapski, Małgorzata Wójcik-Stasiak, Paweł Klincewicz, Jacek Januszczyk, \\ Wojciech Wołyniec, Marcin Renke, Karolina Trzeciakowska-Aziz
}

Department of Occupational and Internal Medicine, Institute of Maritime and Tropical Medicine in Gdynia, Medical University of Gdansk, Poland

In accordance to the regulation of the Minister of Transport, Construction and the Maritime Economy [1], the University Centre of Maritime and Tropical Medicine (UCMTM) in Gdynia was designated to provide distance assistance and support for seafarers as a Maritime Telemedical Assistance Service (TMAS). The TMAS is responsible for giving medical advices via radio, especially for help in proper diagnosis and treatment, making recommendations comprising the ship course or immediate transport to shore-based medical facility with regard to the patient condition. Moreover, TMAS cooperates with Search and Rescue Service providing medical advice, when necessary.

In 2013, 28 patients were assisted by TMAS. Chest pain, fever and work accidents were the most frequent ( $17 \%$ each of them) cases, followed by mental disorder, anuria and parasitic diseases. These results are similar to reports from different TMAS services - injuries are less common than diseases [2, 3]. These data, together with the fact that cardiovascular disease is the most frequent cause of death of seafarers [4] indicates the importance of preventive examinations in this field. It seems that proper periodic medical examination, together with the general car- diovascular death risk assessment (SCORE), should reduce the possibility of making wrong decisions when evaluating the capacity for work [5].

During the first year of activity, TMAS met with considerable interest from sailors and shipowners. The number of notifications in 2014 continues to grow along with the dissemination of information about the TMAS activities.

\section{REFERENCES}

1. Regulation of the Minister of Transport, Construction and the Maritime Economy: http://bip.transport.gov.pl/pl/bip/akty_prawne/transport_morski/rozporzadzenia/d2012000011101/ px_d2012000032001.pdf.

2. Lateef F, Anantharaman V. Maritime Radio-Medical Services: The Singapore General Hospital Experience. Am J Emerg Med 2002; 20:349-351.

3. Horneland A. Maritime telemedicine: where to go and what to do. Int Merit Health 2009; 60: 36-39.

4. Grappasonni I, Petrelli F, Amenta F. Deaths on board ships assisted by the Centro Internazionale Radio Medico in the last 25 years. Travel Medicine and Infectious Disease 2012; 10: 186-191.

5. Rosik E, Jaremin B, Szymańska K. Can general cardiovascular risk evaluation facilitate the assessment of fitness for work and contribute to the reduction of cardiovascular incidents among seamen and fishermen? Article for discussion. Int Marit Heath 2006; 57: 1-4. 